\title{
Understanding farmers' groundwater attitudes for better groundwater management
}

\author{
M. E. Varua ${ }^{1}$, J. Ward ${ }^{2} \&$ B. Maheshwari ${ }^{3}$ \\ ${ }^{1}$ School of Business, University of Western Sydney, Australia \\ ${ }^{2}$ Commonwealth Scientific and Industrial Research (CSIRO), Australia \\ ${ }^{3}$ School of Science and Health, University of Western Sydney, Australia
}

\begin{abstract}
In India, many farmers rely on groundwater for agricultural production. The individually constructed and managed tube well access to groundwater in hard rock aquifers has enabled the majority of these farmers to improve farm incomes and diversify livelihoods. Extensive groundwater exploitation coupled with the lack of institutional rule to establish new wells and regulate pumping levels by individual well owners had led to over extraction of the resource. This paper presents results of the study conducted in the states of Gujarat and Rajasthan to examine farmers' attitudes to groundwater use and management; and to test whether their attitudes across catchments are the same. A hierarchical cluster analysis of groundwater attitude held by survey respondents in Megraj (Gujarat) and Dharta (Rajasthan) watersheds was utilised to ascertain this. The results show that there are four distinct clusters present in each watershed. In addition, preferred water management by cluster membership is reported. The paper concludes that there is a need to account for attitudinal diversity when designing groundwater policies and processes to assist communities shape coordinating instruments to sustainably manage local aquifers.

Keywords: groundwater, groundwater attitudes, hierarchical cluster analysis, water management, aquifers, diversity, cluster membership, watersheds.
\end{abstract}

\section{Introduction}

The use of groundwater in agriculture has contributed to Indian rural poverty alleviation by enabling farmers to better manage episodic deficiencies in monsoonal rainfall, avoid drought related crop losses and engage in dry-season 
irrigation. Groundwater exploitation has enabled farmers to supplement their irrigation requirements and to cope with the seasonal variance and reliability of natural and impounded surface supplies. The access to groundwater has helped poorer farmers to increase their agricultural production and incomes, enhance their opportunities to diversify their income base and reduce vulnerability against seasonal variations of agricultural production and external shocks such as drought, late monsoon onset and shortened monsoonal seasons.

In the last three decades, India has recorded a rapid increase in population growth rate that led to a substantial increase in water demand for domestic and food production. The extensive increase in water demand combined with easy access to subsidised electricity and cheap pumps led to widespread tube well drilling activities across the country. In response, a range of village level onground works to recharge groundwater continue to be implemented throughout India as part of the Government of India's 'Mahatma Gandhi National Rural Employment Guarantee Act' (MNREGA), which seeks to enhance livelihood opportunities while developing a durable groundwater asset base. A significant part of the investment through MNREGA is for enhancing long-term, local water security by on-ground structures such as check dams, percolation tanks, surface spreading basins, pits and recharge shafts or managed aquifer recharge (MAR) [1] to supplement natural aquifer recharge processes [2]. Shah [3] notes that MAR infrastructure commissioned to enhance aquifer recharge has generally only slowed the decline in aquifer depletion. Watershed development has been promoted by the Government of India as a way of improving livelihoods. However, increasing groundwater scarcity and intense competition among users of groundwater are putting the poor and most vulnerable households in irrigated areas at risk.

The notion of groundwater as a privately managed resource, with informal rights vested with the individual and associated with land rights, coupled with the absence of instruments to coordinate, constrain and enforce individual extractions has led to an exploitative extraction regime that exceeds recharge potential [3]. The absence of state regulations or markets to coordinate the operation of individual wells has focussed attention on devolved administration and community level institutions as the primary loci for sustainable groundwater management.

Ostrom [4], Bowles and Gintis [5] and Ward and Dillon [6] contend that community crafted groundwater institutions appeal to, and mobilise individually held attitudes and motivations that reinforce collective action. However the underpinning attitudes that guide Indian irrigator's willingness to participate and cooperate in community based groundwater management is one critical scale that has received limited attention. Empirically tested theoretical frameworks from cognitive and social psychology indicate that behaviour, decision making and actions are shaped partially on individually held attitudes expressed as social norms $[7,8]$.

The Managed Aquifer Recharge through Village level Intervention (MARVI) research project focussed on developing a trans-disciplinary participatory approach to assist communities manage the supply and demand management of 
groundwater in the Dharta (Rajasthan) and Meghraj (Gujarat) watersheds [9]. The project has investigated the spatial extent, water quality characteristics and hydrological dynamics of the Meghraj and Dharta hard rock aquifers, undertaken school education programmes, eliciting of traditional knowledge, training of villagers in well monitoring and community consultation to ascertain the potential of managed aquifer recharge for recharge augmentation. This paper reports an analysis of groundwater attitudes of individual well owners, derived from a social and economic survey conducted as part of the MARVI research program [9].

This paper investigates whether attitudes towards groundwater management and practice are consistent across the watershed. Relatively homogenous attitudes would suggest that a uniform participatory approach could assist the two watershed communities craft consistent rules to manage groundwater such as well placement, well operation, monitoring and standardised sanctions and negotiations within and between management levels.

\section{Theoretical foundations}

The multiple, jointly produced benefits associated with groundwater can be classified as a common pool resource, partially characterised by an informal right to utilise extracted or appropriated water sourced from privately owned wells. Informal rights to extract groundwater are conferred by well construction (costs incurred by individuals) and land ownership. A substantial component of groundwater confers a mutually shared benefit to both owners and non-owners of informal extractive rights, which is both costly to exclude beneficiaries (a characteristic shared with public goods) and subject to rival or subtractable consumption (a characteristic shared with private goods). When joint outcomes depend on multiple actors limiting groundwater extractions that are costly and difficult to quantify and policy instruments are deficient in constraining groundwater extractions, incentives exist for individuals to act opportunistically, often appropriating to a level where aggregate overuse reduces overall groundwater benefits. A social dilemma occurs when individuals are tempted by short term gains to over appropriate groundwater, thereby imposing group shared costs on the common pool community [4]. Individual over extraction will eventually lead to reduced benefits for all.

A lack of regulatory or market based institutional rules to coordinate and enforce pumping levels by individual well owners to meet socially agreed levels of extraction has led to over extraction, threatening both future groundwater availability and dependent livelihoods. The failure to establish and negotiate sustainable abstraction rates coupled with subsidised rural electrification and lower pump prices have amplified the common pool management dilemma, by increasing extraction rates, the number of individual well owners and increased well proximity. The autonomous, uncoordinated operation of individual wells has increasingly focussed attention on community level institutions as the primary loci for improved and coordinated groundwater management. 
Bromley [10], Ostrom [4], Bowles and Gintis [5] and Poteete et al. [11] articulate an alternative arrangement to market based and regulatory approaches, proposing that common pool resources can be effectively managed if information, communication and sanctioning options are available to those using the resource. Ostrom [4] developed design principles of robust, self-organized irrigation systems, emphasising clearly-defined boundaries; proportional equivalence between benefits and costs; ability of irrigators to set and modify rules; monitoring; graduated sanctions; conflict resolution mechanisms; external recognition of rights to organize and nested enterprises.

The corpus of scholarship introduces two contrasting strategies to align sustainable aquifers and devolved community groundwater management: 1) determine a hydrological level that meets sustainability criteria and assess the potential of the institutional level for self-organised groundwater management; and 2) select an institutional level that meets self-organised coordination and asses the sustainability of the hydrological level. Understanding the spatial extent, characteristics and hydrological dynamics of the aquifer is fundamental to the execution of both strategies. In addition, understanding the diversity of individually held attitudes towards groundwater management and practices is essential in order to ascertain the extent farmers will comply with outcomes agreed by the common pool, groundwater community.

\section{The study area}

The work reported here was conducted in the Meghraj watershed in Aravalli district, Gujarat, and the Dharta watershed in Udaipur district, Rajasthan (Figure 1). Both watersheds have a semi-arid climate, with the average annual rainfall in excess of $600 \mathrm{~mm}$, but more than $90 \%$ of this rainfall occurs during the monsoon months of July through September.

Most farmers in the two watersheds grow maize, black gram, mungbean, guar, soybeans (recently introduced) and vegetables as Kharif crops during the rainy season. Wheat, gram and mustard are the main Rabi crops grown during the winter season. Farmers who have access to groundwater (and in some instances canal water) grow two crops a year and those who have access to water supplies throughout the year also grow some summer crops such as vegetables and fodder.

The occurrence and distribution of rainfall in both the Meghraj and Dharta watersheds is highly uneven in both time and space. Kharif crops are mainly dependent on the monsoon and are often at risk of either complete or partial crop failure due to monsoonal variance, manifest as inadequate rainfall, or rainfall not occurring at a critical stage of crop growth. Therefore, the uneven and erratic distribution of rainfall introduces a major challenge to growing crops successfully and to sustain current livelihoods. When rainfall does not occur at the right time or in the required amount, supplementary irrigation, also called 'life saving irrigation', using rainwater stored on the surface or drawn from the underground aquifer systems is crucial in avoiding crop failure [3]. 


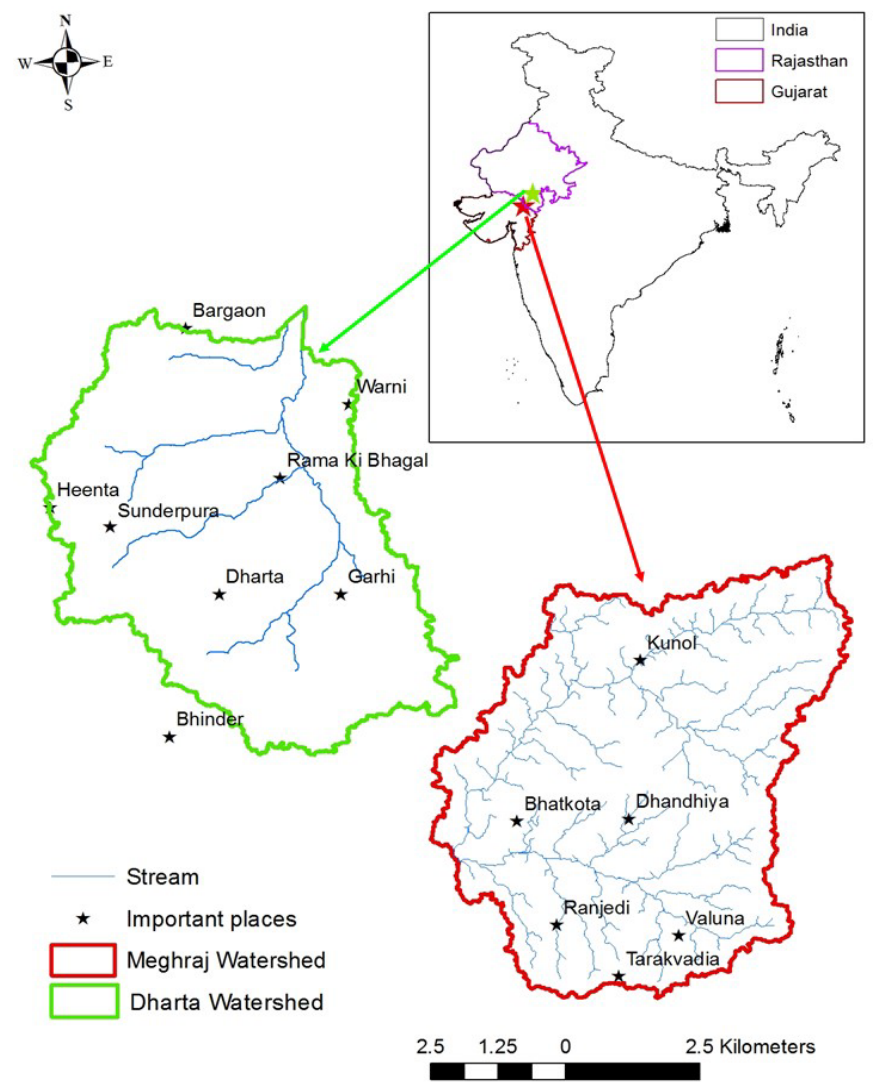

Figure 1: The Meghraj and Dharta watersheds. (The inset map shows the location of the watersheds in the states of Gujarat and Rajasthan in India.)

\section{Methodology}

Local community leaders and extension workers contributed to participatory community assessments in the study sites to construct sample frames of case study households reliant on groundwater for agricultural production. A sample of 501 households from eleven (11) villages of the Meghraj block of Gujarat were randomly drawn from the sample frame and surveyed through face to face interviews. Approximately $21-24 \%$ of the households were interviewed for each village. A sample of 300 randomly selected households was interviewed from the five (5) villages of the Vallabhnagar tehsil of Udaipur district. Respondent households represent $24-29 \%$ of households in each village. Interviewees were either household heads or members who have made decisions on behalf of their household members. Forty one interviews were excluded in the Dharta watershed due to non-completion or missing values $(n=259)$. Combined samples 
of 760 households were used in the survey analysis. Data were collected through voluntary, face to face interviews of 1.5 to 2 hour duration, using a structured questionnaire (available on request). Ethical approval for the survey was granted by the Maharana Pratap University of Agriculture and Technology, Udaipur, Rajasthan. Attitudes to groundwater management and practices were elicited through a series of 11 yes/no interview questions (Table 1).

Table 1: Questions to elicit groundwater attitudes.

1. How likely is it that your children will take over your farm in the future?

2. Do you think that increasing the depth of your well has had an impact on your neighbours?

3. Will the current depth of well/tube-well be sufficient in the next 5 years for your current cropping pattern?

4. Is MAR the best way to maintain your well?

5. Is efficient water use the best way to maintain your well?

6. Has your neighbour's groundwater use reduced the amount of water in your well?

7. Would you be willing to share the water and costs of a recharge scheme with other farmers close to you?

8. Would you be willing to reduce the number of watering if it meant that water would be assured for your children?

9. If your managed recharge scheme increases the water available for your neighbours, should they compensate you?

10. If your neighbours managed recharge scheme increases the water in your well, should you pay them?

11. Would you be willing to adopt a new groundwater management scheme that shared water and costs fairly amongst all irrigators in your village?

The null hypothesis that attitudes towards groundwater management and practice are consistent across two the watershed and village was tested. Cluster analysis was used in this study to segment respondents into relatively homogeneous groups of households/farmers based on their attitudes to the 11 groundwater management, practices and use questions (Table 1). To account for ambient attitudinal diversity, the null hypothesis was accepted if the number of statistically determined, discrete segments was less than or equal to $2(\leq 2)$; a greater than $2(>2)$ segments implied rejection of the null hypothesis.

Ward's minimum variance method [12] represents an example of agglomerative hierarchical cluster analysis, which treats each case as a singleton cluster at the outset and then successively merges pairs of clusters until all clusters have been merged into a single cluster that contains all cases [13, 14]. Squared Euclidean distance estimated Cluster distances and the final number of clusters was derived by frequency analysis of membership and dendogram analysis. A two cluster solution would support the null hypothesis; conversely rejected by a multiple cluster solution. 


\section{Discussion of results}

Hierarchical cluster analysis revealed a four cluster solution where cluster membership was predicted by the 11 groundwater questions specified as X-axis variables in Figure 2; the $y$ axis indicates the composition and relative values of yes responses to the 11 groundwater attitudinal variables across the four clusters.

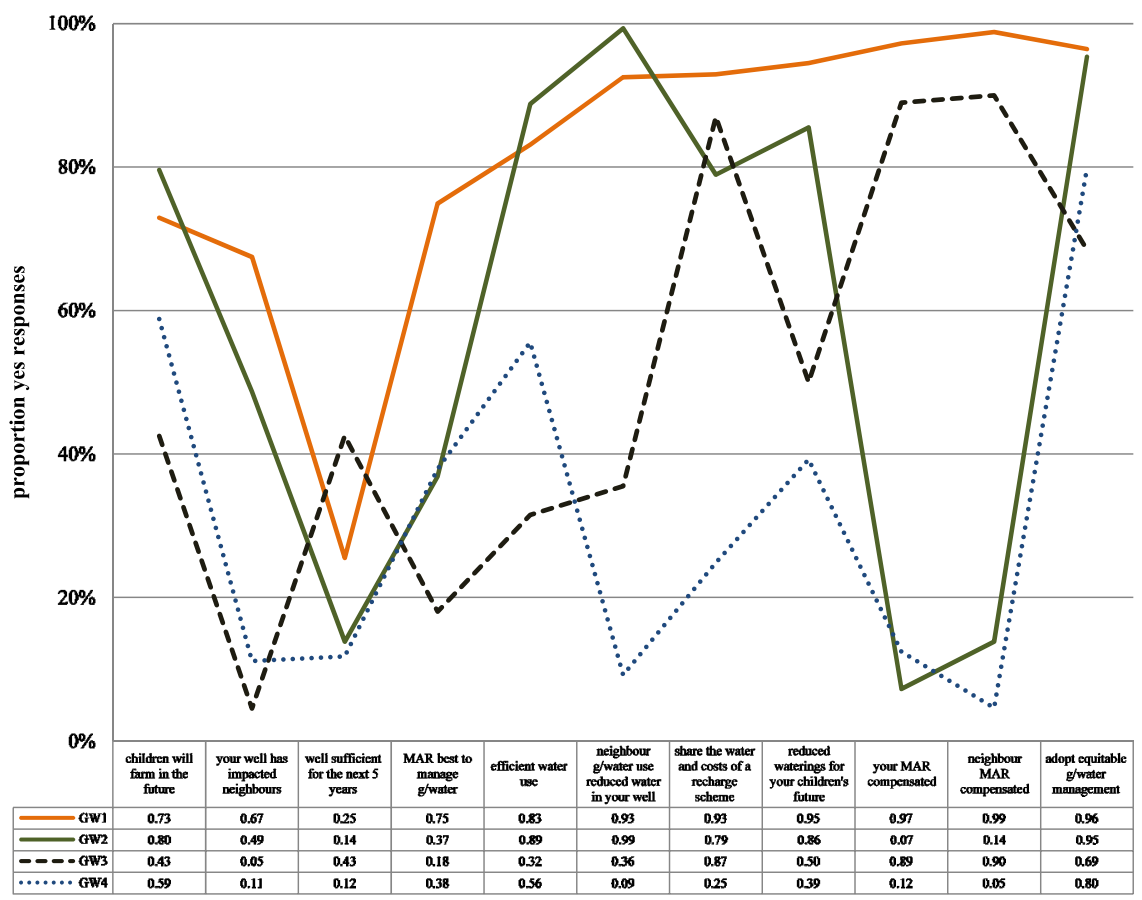

The legend represents cluster descriptors: GW1: Future, compensation, MAR; GW2: Future, noncompensation, water efficiency; GW3: present, compensation; and GW4: present, noncompensation, limited well connectivity.

Figure 2: Cluster attributes based on respondent ground water use and attitudes.

The future, compensation, MAR cluster (GW1) is typified by high likelihood of children taking over the farm $(0.73=$ proportion of yes responses $)$, the belief that increasing the depth of the well had a high impact on neighbours (0.67), judge MAR as the best way to maintain the well $(0.75)$, think that neighbour groundwater use reduced water in the well (0.93) and also believe that that self (0.86) and neighbour (0.99) constructed MAR schemes be compensated. Respondents assigned to GW1 are also prepared to reduce current water use to ensure future water for their children (0.95).

Membership in the future, non-compensation, water efficiency cluster (GW2) is characterised by belief in a high likelihood of children taking over the farm (0.80), the belief that increasing the depth of the well had a moderate impact on 
neighbours (0.49), judge water use efficiency as the best way to maintain the well (0.89), and do not believe that self (0.07) and neighbour (0.14) constructed MAR schemes be compensated. Respondents assigned to GW2 are also prepared to reduce current water use to ensure future water for their children $(0.86)$.

The present, compensation cluster (GW3) is characterised by respondents belief in a relatively low likelihood of children taking over the farm in the future (0.43), do not believe that increasing the depth of the well will have an impact on neighbours well (0.36), do not think that MAR is the best way to manage groundwater (0.15), do not deem that efficient water use is the best way to maintain the well (0.32) but expect that MAR schemes constructed by neighbours (0.90) and self (0.89) be compensated.

The present non-compensation, limited well connectivity cluster (GW4) is characterised by respondents belief in a relatively moderate likelihood of children taking over the farm in the future (0.59), do not believe that increasing the depth of their well impacted on neighbours well (0.09) and their neighbour's water use did not affect water volumes in their own well (0.11), and are not prepared to reduce current water use for their children's future water use. Respondents assigned to GW4 did not believe that self (0.12) and neighbour (0.05) constructed MAR schemes be compensated.

The relative proportions of groundwater cluster membership of respondents located in the two watersheds are detailed in Table 2. Cluster membership of the Meghraj respondents is relatively evenly distributed across the groundwater attitude typology: $33.2 \%$ of respondents were assigned membership in the future, compensation, MAR management cluster (GW1), 27.8\% in the future, noncompensation, water efficiency cluster (GW2); $10.8 \%$ in the present, compensation cluster (GW3) and $28.2 \%$ in the present, non-compensation, limited well connectivity cluster (GW4). The Dharta respondents were characterised by high proportional membership of $56.4 \%$ in cluster GW3 and $34.4 \%$ in cluster GW1 and low proportional membership in clusters GW2 and GW4.

Table 2: Cluster membership by watershed.

\begin{tabular}{|c|c|c|}
\hline & $\begin{array}{c}\text { Meghraj } \\
\text { watershed }\end{array}$ & $\begin{array}{c}\text { Dharta } \\
\text { watershed }\end{array}$ \\
\hline Cluster & $\%(\mathrm{n}=500)^{\mathrm{a}}$ & $\%(\mathrm{n}=259)$ \\
\hline Cluster $(\mathbf{G W 1})$ : Future, compensation, MAR & $33.2 \%(166)$ & $34.4 \%(89)$ \\
\hline $\begin{array}{c}\text { Cluster }(\mathbf{G W 2}) \text { : Future, non-compensation, } \\
\text { water efficiency }\end{array}$ & $27.8 \%(139)$ & $5.0 \%(13)$ \\
\hline Cluster $(\mathbf{G W 3 ) : ~ P r e s e n t , ~ c o m p e n s a t i o n ~}$ & $10.8 \%(54)$ & $56.4 \%(146)$ \\
\hline $\begin{array}{c}\text { Cluster }(\mathbf{G W 4}): \text { Present, non-compensation, } \\
\text { limited well connectivity }\end{array}$ & $28.2 \%(141)$ & $4.2 \%(11)$ \\
\hline
\end{tabular}

${ }^{\mathrm{a}}$ Column \%.

In Table 3, Kruskal Wallis analysis ( $\mathrm{K}$ statistic $>57.25, \mathrm{df}_{3}, \alpha=0.05$ ) rejected the null hypothesis that there are no significant differences in the distribution of 
response rankings across the groundwater clusters for all attitudinal variables. Dunn's pairwise test between pairs of groundwater clusters indicated all other pairwise comparisons are significantly different except GW1 and GW2 for the variable "How likely is it that your children will take over your farm in the future?" The non-parametric analysis indicates the clusters represent statistically discrete segments of groundwater attitudes held by responding farmers in the two watersheds.

Table 3: Kruskal Wallis non-parametric test of cluster variables.

\begin{tabular}{|c|c|c|c|c|c|}
\hline Ground water attitude variable & Kruskal Wallis & GW1 & GW2 & GW3 & GW4 \\
\hline $\begin{array}{l}\text { How likely is it that your children will } \\
\text { take over your farm in the future? }\end{array}$ & $264.45^{\mathrm{a} * *}$ & A & $\mathrm{AB}$ & $\mathrm{C}$ & $\mathrm{D}$ \\
\hline $\begin{array}{l}\text { Do you think that increasing the depth } \\
\text { of your well has had an impact on your } \\
\text { neighbours? }\end{array}$ & $247.66^{* *}$ & A & $\mathrm{B}$ & $\mathrm{C}$ & $\mathrm{CD}$ \\
\hline $\begin{array}{l}\text { Will the current depth of well/tube-well } \\
\text { be sufficient in the next } 5 \text { years for your } \\
\text { current cropping pattern? }\end{array}$ & $57.25^{* *}$ & $\mathrm{AB}$ & B & $\mathrm{C}$ & $\mathrm{BD}$ \\
\hline $\begin{array}{l}\text { Is MAR the best way to maintain your } \\
\text { well? }\end{array}$ & $158.10^{* *}$ & A & $\mathrm{B}$ & $\mathrm{C}$ & $\mathrm{BD}$ \\
\hline $\begin{array}{l}\text { Is efficient water use the best way to } \\
\text { maintain your well? }\end{array}$ & $179.50 * *$ & $\mathrm{~A}$ & $\mathrm{AB}$ & $\mathrm{C}$ & $\mathrm{D}$ \\
\hline $\begin{array}{l}\text { Has your neighbour's groundwater use } \\
\text { reduced the amount of water in your } \\
\text { well? }\end{array}$ & $431.86^{* *}$ & A & $\mathrm{AB}$ & $\mathrm{C}$ & $\mathrm{D}$ \\
\hline $\begin{array}{l}\text { Would you be willing to share the water } \\
\text { and costs of a recharge scheme with } \\
\text { other farmers close to you? }\end{array}$ & $264.45 * *$ & A & $\mathrm{B}$ & $\mathrm{ABC}$ & $\mathrm{D}$ \\
\hline $\begin{array}{l}\text { Would you be willing to reduce the } \\
\text { number of watering if it meant that } \\
\text { water would be assured for your } \\
\text { children? }\end{array}$ & $196.78 * *$ & A & $\mathrm{AB}$ & $\mathrm{C}$ & $\mathrm{CD}$ \\
\hline $\begin{array}{l}\text { If your managed recharge scheme } \\
\text { increases the water available for your } \\
\text { neighbours, should they compensate } \\
\text { you? }\end{array}$ & $537.49 * *$ & A & $\mathrm{B}$ & $\mathrm{AC}$ & $\mathrm{BD}$ \\
\hline $\begin{array}{l}\text { If your neighbours managed recharge } \\
\text { scheme increases the water in your well, } \\
\text { should you pay them? }\end{array}$ & $567.79 * *$ & A & $\mathrm{B}$ & $\mathrm{AC}$ & $\mathrm{BD}$ \\
\hline $\begin{array}{l}\text { Would you be willing to adopt a new } \\
\text { groundwater management scheme that } \\
\text { shared water and costs fairly amongst } \\
\text { all irrigators in your village? }\end{array}$ & $87.49 * *$ & A & $\mathrm{AB}$ & $\mathrm{C}$ & $\mathrm{D}$ \\
\hline
\end{tabular}

${ }^{a}$ Kruskal Wallis test statistic $\mathrm{K}$; degrees freedom $=3$; ** significant at $\alpha=0.05$.

There are no significant differences $(\alpha=0.05)$ between columns with the same letter. 
The study also identified the preferred groundwater management agency by cluster membership. In Meghraj, GW1, GW2 and GW4 cluster members nominated the Panchayat and village community as their first two choices to help select a new ground water management system. Panchayat is a village level local government elected every five years by the village community. Those farm households belonging to GW3 preferred the Panchayat as well but listed a research institute as their second choice. Likewise, when asked who should manage and coordinate the right to access the use of ground water, members of clusters GW2 and GW4 proposed the regional government and the village community while GW1 members believe that it should be the individual well owners followed by the regional government. In contrast, GW3 members proposed the regional water council and the individual well owners.

Dharta farm households assigned to clusters GW1 and GW3 preferred the Panchayat and neighbours to help choose the new ground water management system while the Panchayat and a research institute were selected by members of the GW2 and GW4 clusters. Finally, when questioned about who should manage and coordinate the right to access the use of ground water, GW1 and GW3 members proposed the regional government and Panchayat. The regional government was voted by GW2 and GW4 members as their first preference; GW2 nominated the village community as the second choice and GW4 nominated the local water council.

\section{Conclusions}

The survey data collected in this study allowed the testing of the null hypothesis that groundwater attitudes were consistent across the Meghraj and Dharta watersheds in Gujarat and Rajasthan respectively and as such this implies that a uniform approach to manage groundwater across multiple hydro-geological settings in these watersheds could be implemented to assist communities craft rules and strategies to reduce over-extraction of groundwater at the village level. Hierarchical cluster analysis of attitudes held by survey respondents about the use and management of groundwater revealed four statistically discrete clusters, rejecting the null hypothesis. In conclusion, the study highlights the need to account for attitudinal diversity when designing groundwater policies and processes to assist communities craft coordinating instruments to sustainably manage local aquifers.

\section{References}

[1] Dillon, P., Pavelic, P., Page, D., Beringen H. and Ward J. Managed Aquifer Recharge: An Introduction, Waterlines Report No 13, Feb 2009. http://archive.nwc.gov.au/library/waterlines/13

[2] MNREGA, Mahatma Gandhi National Rural Employment Guarantee, 2014. Act. http://www.nrega.ap.gov.in/

[3] Shah, T. India's groundwater irrigation economy: The Challenge of balancing livelihoods and environment, Handbook on Environmental 
Economics in India. New Delhi, Chopra, K. and Dayal, V. (eds). India: Oxford University Press, 2008.

[4] Ostrom, E. Crafting institutions for self-governing irrigation systems. San Francisco: Institute for Contemporary Studies, 1992.

[5] Bowles, S. and Gintis, H. Social capital, moral sentiments and community governance (ch 13), Moral sentiments and material interests: the foundations of cooperation in economic life eds H. Gintis, S. Bowles, R. Boyd. R. and E. Fehr, MIT series Economic learning and social evolution; MIT Press: Cambridge, Mass, 2005.

[6] Ward, J. and Dillon, P. Design principles to coordinate managed aquifer recharge with natural resource management policies in Australia. Hydrogeology Journal, 20(5), pp. 943-956, 2012.

[7] Schwartz, S.H. Universals in the content and structure of values: theory and empirical tests in 20 countries, Advances in Experimental ed. M. Zanna, 1992.

[8] Stern, P.C., Dietz, T., Abel, T., Guagnano, G.A. and Kalof, L. A value belief norm theory of support for social movements: The case of environmental concern. Human Ecology Review, 6, pp. 81-97, 1999.

[9] Maheshwari, B., Varua, M., Ward, J., Packham, R., Chinnasamy, P., Dashora, Y., Dave, S., Soni, P., Dillon, P., Purohit, R., Hakimuddin, Shah T., Oza, S., Singh, P., Prathapar, S., Patel, A., Jadeja, Y., Thakar, B., Kookana, R., Grewal, H. and Chew, M. The role of transdisciplinary approach and community participation in village scale groundwater management: insights from Gujarat and Rajasthan, India, Water, 6(11), pp. 3386-3408, 2014.

[10] Bromley, D.W., Environment and the Economy: Property Rights and Public Policy. Blackwell: Cambridge, USA. 1991.

[11] Poteete, A.R., Janssen, M.A. and Ostrom, E., Working together: collective action, the commons, and multiple methods in practice. Princeton University Press: Princeton, 2010.

[12] Ward, J.H., Jr. Hierarchical Grouping to Optimize an Objective Function, Journal of the American Statistical Association, 58, pp. 236-244, 1963.

[13] Everitt, B.S., Landau, S. and Leese, M. Cluster Analysis, 4th Edition, Oxford University Press, Inc.: New York; Arnold: London. ch 4, 2001.

[14] Romesburg, H.C. Cluster analysis for researchers, Lulu Press: North Carolina. pp. 130-135, 2004. 